Penelitian

\title{
Prevalensi dan Faktor Risiko Infeksi Hookworm Zoonotik Pasca Pemberian Anthelmentik pada Anjing
}

\author{
(Prevalence and Risk Factor of Zoonotic Hookworm Infection after \\ Anthelmentic Treatment on Dogs)
}

\author{
Ardilasunu Wicaksono ${ }^{1^{*}}$, Yusuf Ridwan ${ }^{2,3}$, Ridi Arif ${ }^{2}$
}

\begin{abstract}
'Divisi Kesehatan Masyarakat Veteriner dan Epidemiologi, Departemen Ilmu Penyakit Hewan dan Kesehatan Masyarakat Veteriner, Fakultas Kedokteran Hewan Institut Pertanian Bogor ${ }^{2}$ Divisi Parasitologi, Departemen Ilmu Penyakit Hewan dan Kesehatan Masyarakat Veteriner, Fakultas Kedokteran Hewan Institut Pertanian Bogor

${ }^{3}$ National Zoonosis Center

*Penulis untuk korespondensi: vetsunuedu@gmail.com Diterima 11 Juli 2019, Disetujui 5 Agustus 2019
\end{abstract}

\begin{abstract}
ABSTRAK
Infeksi hookworm pada anjing menjadi masalah penting baik ditinjau dari sisi kesehatan hewan maupun sisi kesehatan masyarakat karena seluruh spesies hookworm pada anjing memiliki potensi zoonosis. Infeksi hookworm merupakan kejadian endemis di wilayah Asia Tenggara dan prevalensi kejadiannya di Provinsi Jawa Barat mencapai 92.5\%. Penelitian ini bertujuan untuk mengukur prevalensi infeksi hookworm pasca pemberian anthelmentik pada anjing dan untuk mengidentifikasi faktor risiko yang memengaruhi kejadiannya. Prevalensi diukur setelah 3 bulan dilakukannya pengobatan kecacingan massal pada anjing di wilayah Kabupaten Sukabumi. Penelitian ini merupakan kajian lintas seksional dengan mengambil 100 sampel feses anjing untuk mengamati keberadaan telur hookworm menggunakan metode flotasi sederhana dan melakukan wawancara kepada pemilik anjing untuk mengidentifikasi faktor risiko. Data penelitian dianalisis secara deskriptif dan analitis menggunakan Uji Chi Square dan menghitung odds ratio. Hasil penelitian menunjukkan bahwa prevalensi infeksi hookworm setelah pemberian anthelmentik masih sebesar 21.0\% (SK 95\%: 14.2- 30.0\%). Infeksi pada anjing muda (12\%) lebih tinggi dari anjing dewasa (9.0\%), anjing berburu (14.0\%) lebih tinggi dari anjing penjaga (7.0\%), area pegunungan (17.0\%) lebih tinggi dari pesisir pantai (4.0\%), dan kontak dengan anjing liar (20.4\%) lebih tinggi dari tidak ada kontak (2.0\%). Faktor yang signifikan memengaruhi kejadian infeksi hookworm adalah topografi wilayah pemeliharaan $\left(\chi^{2}=4.448, p=0.035\right)$ yang mana anjing yang dipelihara di area pegunungan memiliki kemungkinan terinfeksi 3.381 (SK 95\%: 1.043-10.960) kali dibandingkan area pesisir pantai. Penelitian ini menunjukkan bahwa penggunaan anthelmentik masih belum dapat memberantas infeksi hookworm dikarenakan beberapa faktor dan faktor risiko yang paling berpengaruh adalah topografi lingkungan pemeliharaan anjing.
\end{abstract}

Kata kunci: hookworm zoonotik, prevalensi, anthelmentik, anjing, faktor risiko

\begin{abstract}
Hookworm in dogs is very important not only from the point of animal health but also from the perspective of public health, since all species of hookworms in dogs are zoonotic potential. Infection of hookworm in dogs is endemic in Southeast Asia and the prevalence in West Java Indonesia reached 92.5\%. This study was aimed to measure the prevalence of hookworm infection after anthelmintics treatment and to identify the factors which influence the incidence. The prevalence was measured after 3 months of dog mass deworming in Sukabumi District, West Java. A cross-sectional study was conducted by collection of 100 dog stool samples to identify hookworm eggs using simple flotation methods and by interview of dogs' owner to identify the risk factors. The data were analyzed descriptively and analytically using Chi Square Test and odds ratio. The results showed that the prevalence of hookworm infection after anthelmintic treatment was still $21.0 \%$ (95\% Cl: $14.2-30.0 \%)$. The incidence in puppies (12.0\%) was higher than adult (9.0\%), hunting dogs (14.0\%) was higher than house guarding dogs (7.0\%), highland area (17.0\%) was higher than seaside area (4.0\%), and contact with stray dogs (20.4\%) was higher than no contact (2.0\%). The significant factors that influenced the hookworm incidence was the topography $\left(\chi^{2}=4.448, p=0.035\right)$ whereas highland area had risk 3.381 ( $\left.95 \% \mathrm{Cl}: 1.043-10.960\right)$ times than in seaside. The conclusions were anthelmintics treatment still can't eliminate hookworm infection because of several influence factors and the significant factor was the topography of dogs reared area.
\end{abstract}

Keywords: zoonotic hookworm, prevalence, anthelmintic, dogs, risk factor 


\section{PENDAHULUAN}

Infeksi hookworm pada anjing merupakan masalah yang serius bagi dunia kesehatan, baik dari sisi kesehatan hewan maupun kesehatan manusia. Penyakit ini menjadi perhatian bagi kesehatan masyarakat karena seluruh spesies hookworm pada anjing memiliki potensi menular kepada manusia atau bersifat zoonosis (Mahdy et al., 2012; Shepherd et al., 2018). Ancylostoma caninum merupakan salah satu spesies hookworm yang sangat patogen pada anjing yang merupakan parasit gastro-intestinal dan memiliki risiko yang signifikan terhadap penularannya ke manusia. (Kopp et al., 2007)

Di Asia Tenggara, infeksi hookworm pada anjing bersifat endemis sehingga kejadiannya dapat dipastikan selalu muncul. Berdasarkan kajian Erawan et al. (2016), di Indonesia kejadian hookworm pada anjing dilaporkan di Provinsi Jawa Barat dengan prevalensi mencapai $92.5 \%$. Kabupaten Sukabumi merupakan salah satu daerah di Jawa Barat yang memiliki populasi anjing yang cukup banyak. Mayoritas pemeliharaan anjing masyarakat di sana adalah dilepasliarkan sehingga potensi penularan antar hewan tinggi begitupun potensi penularan penyakit ke manusia karena kedekatan anjing dengan pemiliknya (Wicaksono et al., 2018). Salah satu risiko zoonosis yang muncul adalah infeksi hookworm dari anjing yang berada di sekitar masyarakat tersebut.

Salah satu cara pengendalian hookworm adalah dengan pemberian anthelmentik. Sediaan yang banyak digunakan untuk pengobatan kecacingan tersebut pada anjing di seluruh dunia adalah pyrantel (Kopp et al., 2007). Untuk pengobatan pada manusia yang terinfeksi, beberapa sediaan yang direkomendasikan oleh WHO antara lain mebendazole, albendazole, levamisole atau pyrantel (Vercruysse et al., 2011).

Permasalahan muncul dikarenakan pemberian anthelmentik belum dapat dikatakan efektif dalam rangka mengeliminasi penyakit ini di suatu wilayah endemis dikarenakan beberapa masalah seperti adanya resistensi anthelmentik ataupun reinfeksi hookworm setelah dilakukannya pengobatan massal. Dengan demikian, penelitian ini bertujuan untuk mengukur tingkat kejadian dan menganalisis faktor-faktor risiko terkait infeksi hookworm zoonotik pasca pemberian anthelmentik pada anjing di Kabupaten Sukabumi, Jawa Barat.

\section{METODE PENELITIAN}

\section{Disain Penelitian}

Penelitian ini merupakan kajian lintas seksional untuk mengukur kejadian infeksi hookworm pada anjing setelah kurun waktu 3 bulan dilakukan pemberian anthelmentik pada anjing yang terpilih sebagai sampel. Hasil pemeriksaan sampel kemudian dijadikan peubah terikat yang akan dihubungkan dengan faktor-faktor risiko yang berasosiasi terhadap kejadian infeksi tersebut (peubah bebas). Faktor risiko diidentifikasi dengan cara melakukan wawancara kepada pemilik anjing dengan menggunakan kuesioner terstruktur.

\section{Waktu dan Tempat}

Pengambilan sampel dilakukan pada bulan April Juni 2017 di Kabupaten Sukabumi, Provinsi Jawa Barat. Proses pengujian sampel dan analisis data dilakukan bulan Juli - Agustus 2017. Pengujian sampel dilakukan di Laboratorium Helminthologi, Fakultas Kedokteran Hewan, Institut Pertanian Bogor, kemudian analisis data dilakukan di Laboratorium Epidemiologi, Fakultas Kedokteran Hewan, Institut Pertanian Bogor

\section{Sampel Penelitian}

Sampel yang diambil dalam penelitian ini adalah sampel feses dari anjing yang telah diberikan anthelmentik tiga bulan sebelumnya. Sampel diambil secara acak menggunakan teknik penarikan contoh acak sederhana (simple random sampling). Besaran sampel untuk menduga prevalensi infeksi hookworm dihitung dengan rumus (Dohoo et al., 2003):

$$
\begin{array}{ll} 
& \mathrm{n}=\mathrm{z}_{a}{ }^{2} \times \mathrm{p} \times \mathrm{q} / \mathrm{L}^{2} \\
\mathrm{z}_{\alpha}(\text { SK } 95 \%) & =1.96 \\
\mathrm{p} & =\text { prevalensi dugaan } \\
\mathrm{q} & =1-\mathrm{p} \\
\mathrm{L} & =\text { tingkat kesalahan }
\end{array}
$$

dengan asumsi selang kepercayaan 95\%, prevalensi dugaan 93\% (Erawan et al., 2016) dan tingkat kesalahan 5\%, maka didapatkan besaran sampel 100 ekor anjing.

\section{Pengambilan Data Penelitian}

Sampel feses diambil dengan pengulasan rektum anjing menggunakan cotton bud yang telah dibasahi cairan $\mathrm{NaCl}$ fisiologis $0.9 \%$. Anus anjing dikuakkan kemudian cotton bud dimasukkan mencapai rektum 
dengan cara diputar dan ditarik kembali untuk mendapatkan sampel feses. Selanjutnya, sampel feses disimpan di plastik klip dan dimasukkan di dalam cool box untuk ditrasportasikan ke tempat pemeriksaan sampel. Data faktor risiko diambil dengan melakukan wawancara kepada pemilik hewan yang anjingnya terpilih sebagai sampel. Data yang diambil adalah umur anjing, kegunaan anjing, topografi lingkungan pemeliharaan anjing, dan adanya kontak dengan anjing liar. Wawancara dilakukan menggunakan kuesioner yang telah disusun secara terstruktur.

\section{Pemeriksaan Sampel Feses}

Pemeriksaan sampel dilakukan dengan metode flotasi sederhana untuk mendeteksi telur cacing. Larutan flotasi gula garam jenuh dimasukkan ke dalam pot plastik kemudian sampel ulasan rektum dikeluarkan dari plastik klip dan direndam pada larutan flotasi, kemudian didiamkan selama lima menit. Setelah itu, larutan dimasukkan ke dalam tabung reaksi hingga membentuk meniskus cembung. Cover glass diletakkan di atas meniskus cembung larutan flotasi lalu dipindahkan ke gelas objek dan diperiksa di bawah mikroskop. Pengamatan pada mikroskop dilakukan dengan perbesaran 10x pada seluruh permukaan gelas objek dengan menggerakkan slide perlahan dari kanan ke kiri dan dari atas ke bawah.

\section{Analisis Data}

Perhitungan prevalensi dilakukan dengan menghitung proporsi jumlah positif telur cacing dari keseluruhan sampel yang diamati. Untuk identifikasi faktor risiko, hubungan antara faktor-faktor yang diamati dengan hasil pemeriksaan sampel dianalisis menggunakan Uji Chi-Square dan perhitungan Odds Ratio. Analisis data dilakukan dengan menggunakan perangkat lunak Microsoft Excel 2007 dan SPSS for Windows versi 16 .

\section{HASIL}

Hasil penelitian menunjukkan bahwa terdapat 21 sampel positif ditemukan telur cacing Hookworm di bawah pengamatan dari 100 sampel feses yang diamati. Hal ini menunjukkan bahwa tingkat kejadian infeksi hookworm setelah tiga bulan dilakukan pemberian anthelmentik masih sebesar 21.0\% (SK 95\%: $14.2-30.0 \%$ ). Hasil pemeriksaan tersebut dapat dilihat pada Tabel 1.

Peubah-peubah yang diamati dalam penelitian ini yaitu umur hewan, kegunaan hewan, topografi tempat pemeliharaan hewan, dan kontak dengan anjing liar. Peubah-peubah tersebut dikategorikan lalu kemudian dibandingkan proporsi kasus yang positif terinfeksi hookworm. Dari hasil pengamatan tersebut, diperoleh bahwa infeksi hookworm pada anjing muda (12.0\%) lebih tinggi dibandingkan dengan anjing dewasa (9.0\%), infeksi hookworm pada anjing yang digunakan untuk berburu (14.0\%) lebih tinggi daripada anjing yang digunakan untuk menjaga rumah atau ladang (7.0\%) dan hasil negatif diperoleh untuk anjing kesayangan/pet. Kemudian, infeksi hookworm pada anjing yang dipelihara di daerah pegunungan (17.0\%) lebih tinggi dibandingkan dengan anjing yang dipelihara pada daerah pesisir pantai (4.0\%), dan infeksi hookworm pada anjing yang berkontak dengan anjing liar (24.0\%) lebih tinggi daripada anjing yang tidak pernah berkontak dengan anjing liar (2.0\%). Hasil pengamatan tersebut disajikan pada Gambar 1.

Hasil penelitian selanjutnya adalah penentuan faktor risiko yang berhubungan dengan kejadian infeksi hookworm pada anjing tiga bulan pasca pemberian anthelmentik. Dari empat peubah yang diamati, dapat dilihat pada Tabel 2 bahwa umur anjing tidak berpengaruh nyata $(p=0.606)$ terhadap infeksi hookworm begitupun faktor kegunaan anjing yang tidak berpengaruh nyata $(p=0.591)$ terhadap infeksi tersebut. Disamping itu, peubah adanya kontak anjing yang dipelihara dengan anjing liar juga tidak berpengaruh nyata $(p=0.117)$ terhadap adanya infeksi ulang setelah pemberian anthelmentik.

Terdapat satu peubah yang memengaruhi infeksi hookworm pasca tiga bulan pemberian anthelmentik yakni faktor jenis topografi pemeliharaan. Lingkungan pemeliharaan antara wilayah pegunungan dan wilayah pesisir pantai berpengaruh signifikan $(p=0.035)$ terhadap adanya infeksi ulang dari hookworm pada anjing. Hasil penelitian menunjukkan kejadian di wilayah pegunungan lebih tinggi dibandingkan dengan kejadian di wilayah pesisir pantai dengan nilai Odds Ratio 3.381 (1.043 10.960). Hal ini menunjukkan bahwa anjing yang dipelihara di wilayah pegunungan memiliki kemungkinan kembali terinfeksi hookworm sebesar 3.381 kali (1.043 - 10.960) dibandingkan dengan anjing yang dipelihara di wilayah pesisir pantai. 
Tabel 1 Hasil pengamatan infeksi hookworm pada sampel

\begin{tabular}{llcc}
\hline & Hasil & $\mathrm{n}(\%)$ & SK 95\% \\
\hline Infeksi Hookworm & Positif & $21(21.0)$ & $14.2-30.0$ \\
& Negatif & $79(79.0)$ & $71.0-87.0$ \\
\hline & Total & $100(100.0)$ & \\
\hline
\end{tabular}

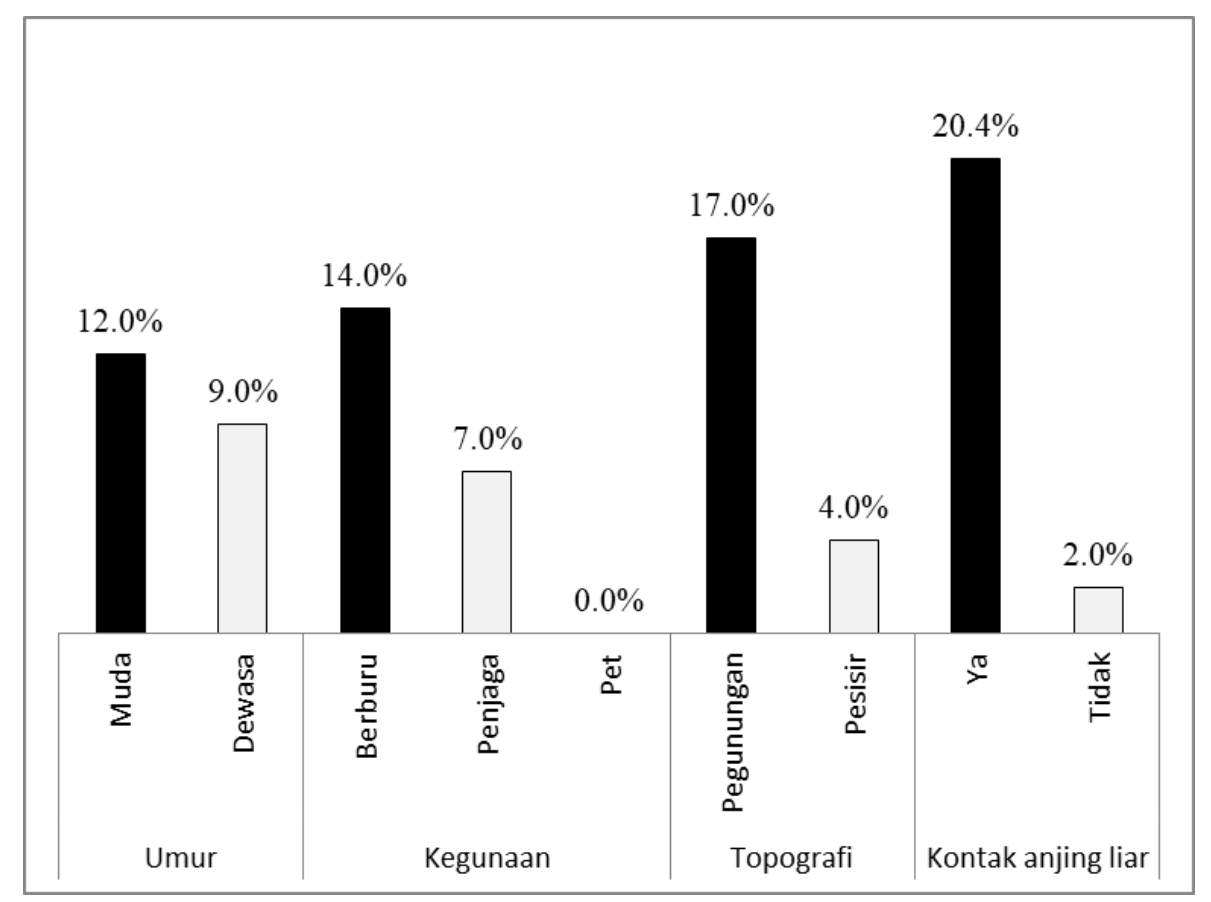

Gambar 1 Kejadian infeksi hookworm pada peubah yang diamati

\section{PEMBAHASAN}

Infeksi hookworm masih terjadi pada anjinganjing yang telah diberikan anthelmentik saat program pengobatan massal yang dilakukan tiga bulan sebelumnya. Dilihat dari sisi efikasi obat yang diberikan, sediaan anthelmentik yang diberikan saat pengobatan massal tersebut adalah fenbendazole, praziquantel dan pyrantel. Menurut Miro et al., (2007), sediaan febantel, pyrantel, dan praziquantel untuk hookworm memiliki efikasi sebesar $90-100 \%$, sedangkan fenbendazole sebesar 99 - 100\%. Kemudian Raza et al., (2018) menyampaikan bahwa pirantel dapat memberikan perlindungan terhadap hookworm dan ascarids yang merupakan cacing yang sering menginfestasi anak anjing yang berumur hingga 16 minggu.

Dugaan yang menyertai hasil penelitian ini terkait masih adanya infeksi hookworm pada anjing adalah adanya resistensi dari anthelmentik yang digunakan, karena sering ditemukannya resistensi anthelmentik dalam pengobatan kecacingan pada hewan-hewan kesayangan seperti anjing dan kucing (Kopp et al., 2007).
Resistensi anthelmentik dapat terjadi karena pemberiannya yang tidak memperhatikan dosis sesuai berat badan hewan, termasuk adanya monitoring keberadaan agen dan pengaruh lokasi yang kurang diperhatikan (Raza et al., 2018). Keberadaan agen di lingkungan juga dapat meningkatkan kemungkinan terjadinya reinfeksi pada anjing.

Hasil pengamatan pada peubah dalam penelitian ini menunjukkan bahwa infeksi hookworm yang terjadi lebih tinggi pada anjing berumur muda $(\leq 1$ tahun) dibandingkan anjing dengan kategori dewasa. Hal ini menunjukkan adanya kemungkinan pengaruh faktor umur terhadap infeksi hookworms, yakni semakin muda umur anjing semakin rentan terhadap infeksi cacing. Hasil serupa dilaporkan di beberapa negara seperti Bangladesh (Shubhagata, 2012), Ethiopia (Endrias et al., 2010); Tanjania (Swai et al., 2010), Argentina (Andresiuki et al., 2007) dan Brazil (Muradian et al., 2005) yang mendukung hasil penelitian ini yakni ancylostomiasis lebih tinggi pada anjing dibawah umur 1 tahun. Prevalensi infeksi hookworms yang lebih tinggi pada anjing muda diduga 
Tabel 2 Hasil analisis identifikasi faktor risiko infeksi hookworm

\begin{tabular}{|c|c|c|c|c|c|c|}
\hline \multirow{3}{*}{ Peubah } & \multicolumn{4}{|c|}{ Infeksi hookworm } & \multirow{3}{*}{$\chi^{2}$} & \multirow{3}{*}{$p$-value } \\
\hline & \multicolumn{2}{|c|}{ Positif } & \multicolumn{2}{|c|}{ Negatif } & & \\
\hline & $\mathrm{n}$ & $\%$ & $\mathrm{n}$ & $\%$ & & \\
\hline \multicolumn{7}{|l|}{ Umur } \\
\hline - Muda ( $\leq 1$ tahun) & 12 & 12.0 & 50 & 50.0 & 0.266 & 0.606 \\
\hline - Dewasa (>1 tahun) & 9 & 9.0 & 29 & 29.0 & & \\
\hline \multicolumn{7}{|l|}{ Kegunaan anjing } \\
\hline - Berburu & 14 & 14.0 & 54 & 54.0 & & \\
\hline - Penjaga & 7 & 7.0 & 23 & 23.0 & 0.637 & 0.591 \\
\hline - Hewan kesayangan & 0 & 0.0 & 1 & 1.0 & & \\
\hline \multicolumn{7}{|l|}{ Topografi pemeliharaan } \\
\hline - Pegunungan & 17 & 17.0 & 44 & 44.0 & 4.448 & $0.035^{*}$ \\
\hline - Pesisir pantai & 4 & 4.0 & 35 & 35.0 & & \\
\hline \multicolumn{7}{|l|}{ Kontak dengan anjing liar } \\
\hline - $\quad \mathrm{Ya}$ & 10 & 20.4 & 27 & 55.1 & 1.819 & 0.177 \\
\hline - $\quad$ Tidak & 1 & 2.0 & 11 & 22.4 & & \\
\hline
\end{tabular}

berkaitan dengan rute infeksi transplacental dan transmammary pada anak anjing. Penyebab lainnya adalah berkaitan dengan faktor kekebalan anjing muda lebih rendah dibandingkan anjing yang lebih tua yang mana anjing tua lebih resisten terhadap infeksi disebabkan imunitas dapatan khususnya di daerah endemik (Borecka, 2005).

Mayoritas anjing di daerah Kabupaten Sukabumi digunakan untuk masyarakat sebagai pendamping untuk berburu babi hutan dan menjaga ladang atau sawah. Dari sisi kegunaan anjing, infeksi hookworm terjadi lebih banyak pada anjing yang digunakan untuk berburu dibandingkan menjaga ladang. Hal ini dapat diakibatkan oleh adanya kontaminasi hookworm pada tanah di daerah sekitar sehingga risiko terinfeksi pada anjing berburu dengan jarak jelajah yang tinggi lebih besar (Menelaos dan Smaragda, 2006).

Dari tempat diambilnya sampel penelitian, dikategorikan lingkungan pemeliharaan anjing berdasarkan topografinya yakni lingkungan pegunungan dan lingkungan pesisir pantai. Kedua keadaan ini merupakan topografi umum di daerah Kabupaten Sukabumi. Hasil penelitian menunjukkan bahwa anjing yang dipelihara di daerah pegunungan menunjukkan persentase infeksi hookworm yang lebih tinggi dibandingkan daerah pesisir pantai. Menurut Raza et al., (2018), Ancylostoma spp. Banyak menginfeksi inang yang hidup pada zona yang lembab dan hangat yang tidak terlalu panas.

Faktor terakhir yang dikaji dalam penelitian ini adalah adanya kontak antara anjing yang dipelihara dengan anjing liar yang tidak berpemilik. Hasil menunjukkan bahwa terdapat perbedaan persentase yang sangat tinggi yakni anjing yang sering atau dapat berkontak dengan anjing liar memiliki persentase lebih tinggi terinfeksi hookworm dibandingkan anjing yang tidak berkontak dengan anjing liar. Hal ini dapat terjadi seiring dengan frekuensi kontak yang tinggi dengan anjing liar yang belum diketahui status kesehatannya yang berakibat kepada risiko transmisi agen dari satu inang ke inang lainnya (Flacke et al., 2013).

Hasil terakhir dari analisis yang dilakukan pada penelitian ini menunjukkan bahwa terdapat satu faktor yang berpengaruh nyata dengan kejadian infeksi hookworm pasca pemberian anthelmentik setelah tiga bulan pada anjing. Dari keempat faktor risiko yang diamati, faktor jenis topografi pemeliharaan memiliki hubungan yang signifikan dengan kejadian infeksi. Hasil penelitian menunjukkan bahwa infeksi di wilayah pegunungan lebih tinggi dibandingkan dengan infeksi di wilayah pesisir pantai yang memperlihatkan bahwa anjing yang dipelihara di wilayah pegunungan memiliki kemungkinan kembali terinfeksi hookworm sebesar 3.381 kali (1.043 - 10.960) dibandingkan dengan anjing yang dipelihara di wilayah pesisir pantai. Hasil ini sesuai dengan hasil penelitian lain bahwa anjing yang dipelihara di daerah sejuk lebih banyak terinfeksi hookworm dan didukung oleh tingkat kelembaban udara yang tinggi. Hal ini diakibatkan oleh adanya penetasan telur dan perkembangan larva yang cepat (Raza et al., 2018).

Menurut Ndokeji et al., (2016), faktor seperti kelembaban lingkungan, temperatur, sinar ultraviolet dan variasi geografis sangat memengaruhi siklus transmisi dari hookworm, faktor 
lainnya juga cukup memengaruhi adalah curah hujan, tipe tanah, dan altitud. Daerah pegunungan yang memiliki temperatur yang lebih rendah dibandingkan dengan daerah pesisir dapat mendukung tahapan dewasa di lingkungan yakni berkembang optimum pada suhu $20-30{ }^{\circ} \mathrm{C}$ (Hossain dan Bhuiyan, 2016). Selain itu, telur hookworm akan menetas lebih baik pada tanah yang lembab seperti pada lingkungan pegunungan (Craig dan Scott 2014). Selanjutnya, kebanyakan larva hookworm tidak dapat bertahan pada suhu di atas $37^{\circ} \mathrm{C}$ (Menelaos dan Smaragda, 2006).

Dengan adanya hasil penelitian ini, diharapkan memberikan informasi bahwa keberadaan infeksi hookworm pada anjing memiliki risiko kesehatan masyarakat yang besar mengingat hookworm bersifat zoonotik. Infeksi hookworm seperti Ancylostoma caninum atau $A$. brasiliense dapat menyebabkan penyakit cutaneous larval migrans yang disebabkan oleh frekuensi kontak antara manusia dan anjing peliharaan (Bowman et al., 2010). Infeksi hookworm terjadi pada 438.9 juta jiwa di dunia setiap tahunnya, dan mengakibatkan tingkat morbiditas yang tinggi baik pada anak-anak maupun dewasa di wilayah endemis (Vercruysse et al., 2011; Hossain dan Bhuiyan, 2016). Masalah ini perlu menjadi perhatian dan dikendalikan untuk meminimalkan risiko penularannya.

Pengendalian infeksi hookworm dapat dilakukan dengan pemberian anthelmentik secara periodik, namun mengingat masih adanya infeksi pasca pengobatan massal seperti yang ditampilkan dalam penelitian ini, maka diperlukan langkah-langkah pengendalian lain. Selain pemberian anthelmentik, pengendalian dapat dilakukan melalui peningkatan pengetahuan dan kepedulian pemilik anjing untuk memberikan perawatan anjingnya lebih baik dengan selalu menjaga sanitasi tempat pemeliharaan.

Kesimpulan dari penelitian ini adalah masih terdapat infeksi hookworm setelah pemberian anthelmentik sebesar 21.0\% (SK 95\%: 14.2- 30.0\%) dengan sebaran kasus yakni infeksi pada anjing muda lebih tinggi dari anjing dewasa, anjing berburu lebih tinggi dari anjing penjaga, area pegunungan lebih tinggi dari pesisir pantai, dan kontak dengan anjing liar lebih tinggi dari tidak ada kontak. Faktor yang signifikan memengaruhi kejadian infeksi hookworm adalah topografi wilayah pemeliharaan yang mana anjing yang dipelihara di area pegunungan memiliki kemungkinan terinfeksi 3.381 (SK 95\%: 1.043-10.960) kali dibandingkan area pesisir pantai.

\section{UCAPAN TERIMA KASIH}

Terima kasih diucapkan kepada Ditjen Dikti yang telah mendanai penelitian ini yang merupakan bagian dari kegiatan Penelitian Unggulan Perguruan Tinggi tahun 2017. Ucapan terima kasih juga disampaikan kepada Dinas Peternakan Kabupaten Sukabumi yang telah membantu kegiatan penelitian ini.

"Penulis menyatakan tidak ada konflik kepentingan dengan pihak-pihak yang terkait dalam penelitian ini"

\section{DAFTAR PUSTAKA}

Andresiuki V, Sardellai N, Denegri G .2007. Seasonal fluctuations in prevalence of dog intestinal parasites in public squares of Mar del Plata city, Argentina and its risk for humans. Revista Argentina de Microbiología 39: 221-224.

Borecka A. 2005. Prevalence of intestinal nematodes of dogs in Wassaw area, Poland. Helmithologica 42: 35-39.

Bowman DD, Montgomery SP, Zajac AM, Eberhard ML, Kazacos KR. 2010. Hookworms of dogs and cats as agents of cutaneous larva migrans. Trends in Parasitology 26: 162-167.

Craig JM, Scott AL. 2014. Helmints in the lungs. Parasite Immunology 36: 463-474.

Dohoo I, Martin W, Stryhn H. 2003. Veterinary Epidemiologic Research. AVC Inc Canada. Prince Edward Island. p39-42.

Endrias Z, Semahegn Y, Mekibib B. 2010. Prevalence of helminth parasites of dogs and owners awareness about zoonotic parasites in Ambo town, central Ethiopia. Ethiopian Veterinary Journal 14: 17-30.

Erawan IGMK, Widyastuti SK, Suartha IN. 2016. Prevalence and Intensity of Infection of Ancylostoma Spp. in Dogs in Java. Indonesia Medicus Veterinus 5:175-181.

Flacke G, Becker P, Cooper D, Gunther MS, Robertson I, Holyoake C, Donaldson R, Warren K. 2013. An infectious disease and mortality survey in a population of free-ranging african wild dogs and sympatric domestic dogs. International Journal of Biodiversity Vol 2013 1-9.

Hossain M, Bhuiyan JU. 2016. Hookworm infection: A neglected tropical disease of mankind. Journal of Advanced Veterinary and Animal Research 3: 297-320. 
Kopp AR, Kotze AC, McCarthy JS, Coleman GT. 2007. High-level pyrantel resistance in the hookworm Ancylostoma caninum. Veterinary Parasitology 143: 299-304.

Mahdy MAK, Lim YAL, Ngui R, Fatimah MRS, Choy SH, Yap NJ, Al Mekhlafi HM, Ibrahim J, Surin J. 2012. Prevalence and zoonotic potential of canine hookworms in Malaysia. Parasites and Vectors 5:88.

Menelaos LA, Smaragda KE. 2006. Prevalence of hookworm parasites in dog from the area of Thessaloniki and their zoonotic importance. Buletin USAMV-CN 63: 297-30.

Miro G, Mateo M, Montoya A, Vela E, Calonge R. 2007. Survey of intestinal parasites in stray dogs in the Madrid area and comparison of the efficacy of three anthelmintics in naturally infected dogs. Parasitology Research. 100: 317-320.

Muradian V, Gennari SM, Glickman LT, Pinheiro SR. 2005. Epidemiological aspects of Visceral Larva Migrans in children living at São Remo Community, São Paulo SP, Brazil. Veterinary Parasitology 134: 93-97.

Ndokeji S, Mazigo HD, Malenganisho W, Todd J, Changalucha J. 2016. Prevalence and intensity of Schistosoma mansoni and hookworm infections among pre-school and school-aged children in llemela District, north-western Tanzania. Tanzania Journal of Health Research 18: 1-8.
Raza A, Rand J, Qamar AG, Jabbar A, Kopp S. 2018. Gastrointestinal Parasites in Shelter Dogs: Occurrence, Pathology, Treatment and Risk to shelterworkers. Animals 8: 1-23.

Shepherd C, Wangchuk P, Loukas A. 2018. Of dogs and hookworms: man's best friend and his parasites as a model for translational biomedical research. Parasites and Vectors 11: 59.

Shubhagata D, Suchandan S, Aungshuman Das G, Masuduzz, AMd. 2012. Prevalence and worm load of enteric helminthiasis on stray dogs of Chittagong Metropolitan, Bangladesh. YYU Veteriner Fakultesi Dergisi 23: 141-145.

Swai ES, Kaaya EJ, Mshanga, DA, Mbise EW (2010). A survey on gastro-intestinal parasites of nondescript dogs in and around Arusha Municipality, Tanzania. International Journal of Animals and Veterinary Advances 3: 63-67.

Vercruysse J, Albonico M, Behnke JM, Kotze AC, Prichard RK, McCarthy JS, Montresor A, Levecke B. 2011. Is anthelmintic resistance a concern for the control of human soil-transmitted helminths? International Journal for Parasitology Drugs and Drug Resistance 1:14-27.

Wicaksono A, llyas AZ, Sudarnika E, Lukman DW, Ridwan Y. 2018. Pengetahuan, Sikap, dan Praktik Pemilik Anjing Terkait Rabies di Kabupaten Sukabumi, Jawa Barat. Jurnal Veteriner 19: 230-241. 